\title{
ESPOSAS INDÔMITAS: A POSTURA FEMININA EM CONTRAPONTO NOS ROMANCES DOM CASMURRO, DE MACHADO DE ASSIS, E O PERDÃO, DE ANDRADINA DE OLIVEIRA
}

\author{
Thiago Moreira Aguiar ${ }^{1}$
}

\begin{abstract}
Resumo: A partir do estudo comparativo de $O$ perdão, de Andradina de Oliveira, e Dom Casmurro, de Machado de Assis, este trabalho pretende traçar um perfil mais conciso dos discursos literários de fins do século XIX e início do XX, buscando compreender as diferenças e semelhanças das visões entre a autoria feminina e masculina, na representação de questões históricas dentro do discurso literário, em especial sobre a questão do próprio gênero feminino e sua atuação na seara da esfera social. Nesse sentido, os impasses da traição e do adultério fizeram-se mais atrativos para se pensar a questão, já que tais atos representam uma fissura no "seio" de um sistema ideológico marcado pela heteronormatividade, simbolizado particularmente pela família burguesa. O aporte teórico vincula-se, principalmente, pelos estudos sobre 0 cânone literário e nas diferentes formas de representação da literatura de autoria feminina, segundo Rita Terezinha Schmidt e Anselmo Peres Alós. A metodologia deste estudo se constitui basicamente com pesquisa bibliográfica, fazendo um levantamento da fortuna crítica dos dois romances além de uma análise contrastiva das obras sob um viés de cunho comparatista, com ferramentas conceituais advindas da teoria feminista. Os pontos que podem ser ressaltados previamente no entrecruzamento das duas obras são as representações distintas dos personagens femininos no processo de identificação com a ideologia dominante e o reconhecimento desigual de seus autores nas instituições literárias.
\end{abstract}

PALAVRAS-CHAVE: Literatura comparada. Teoria feminista. Adultério. Heteronormatividade.

\begin{abstract}
From the comparative study of $O$ perdão, de Oliveira Andradina and Dom Casmurro, Machado de Assis, this paper aims to outline a more concise profile of literary discourses of the late nineteenth and early twentieth centuries, trying to understand the differences and similarities of views between female and male authors in the representation of historical issues within the literary discourse, particularly on the issue of own females and their performance in the harvest of the social sphere. In this sense, the impasses of betrayal and adultery were made more attractive to think about the issue, since such acts represent a crack in the "womb" of an ideological system marked by heteronormativity, particularly symbolized by the bourgeois family. The theoretical framework is linked to mainly by studies of the literary canon and different forms of representation of the female authors of literature, according to

\footnotetext{
${ }^{1}$ Graduado em História pelo Centro Universitário Franciscano. Mestrando em Estudos Literários no Programa de Pós-Graduação em Letras UFSM. E-mail: thiagomoreira.aguiar@gmail.com
} 
Rita Therezinha Schmidt and Anselmo Peres Alós. The methodology of this study is basically composed with literature, making a survey of the critical fortunes of two novels and a and contrastive analysis of the works under a comparative nature of bias, with conceptual tools arising from feminist theory. The points can be pre-stressed in the intersection of the two works are distinct representations of the female characters in the identification process with the dominant ideology and unequal recognition of the authors in the literary institutions.

KEYWORDS: Comparative literature. Feminist theory. Adultery. Heteronormativity.

Já se tornou bastante recorrente no meio acadêmico a importância do resgate de romances que, devido à conjuntura cultural e política em que foram produzidos, acabaram sendo relegados e esquecidos pela crítica literária. Seja através de uma censura explícita, como no caso de um regime militar, ou pelas restrições tácitas de um sistema patriarcal, cada vez mais pesquisadores se debruçam em "alforriar" narrativas obliteradas por determinada conjuntura histórica. Dessa forma, esses romances perfazem novas percepções sociais, permitindo dialogar não somente com o meio em que estão inseridos, mas também com textos canônicos já reconhecidos pela crítica. Fato cada vez mais comum e que vem sendo facilmente percebido nas instituições de ensino superior são disciplinas que buscam dar conta desse processo de repressão textual. Inserido nesse contexto, este artigo pretendese como mais uma forma de elucidar a voz feminina, dentre tantas, que fora ofuscada pelo cenário patriarcal brasileiro, ainda na aurora do século XX.

Andradina de Oliveira (1878-1935) quebrou paradigmas sociais ao se voltar para a produção intelectual em um ambiente que pretendia destinar as mulheres apenas para as tarefas do lar, ou seja, costurando, bordando e cuidando dos filhos. Escritora gaúcha, publicou dois romances no início dos novecentos: O divórcio?, de 1912, e O Perdão, de 1910, além de vários contos, crônicas, biografias e peças teatrais. Fundou o jornal Escrínio, em Bagé, o qual tinha um alto teor feminista e percorreu a América Latina fazendo palestras remuneradas com a temática da condição feminina. Em meio ao emaranhado de críticas literárias que compreendiam apenas escritores homens, Andradina de Oliveira travou combate contra a imposição da vontade 
masculina em seus escritos, estabelecendo a forma de denúncia. Contudo, esses espólios somente foram revisitados no início do século XIX, sob a tutela - não única - da professora Rita Terezinha Schmidt, da Universidade Federal do Rio Grande do Sul, oportunizando uma nova análise crítica sobre a sociedade porto-alegrense da belle époque e do seu contexto literário.

Por outro lado, Machado de Assis (1839 - 1908) encarna o típico cânone literário concernente à época, quando o lugar da intelectualidade pertencia unicamente ao "gênio" masculino, estabelecendo um paradoxo com a escritora gaúcha. Contudo, segundo o historiador Sidney Chalhoub (2005), a carreira do bruxo do Cosme Velho é uma contínua quebra de paradigmas sociais, indo de encontro aos discursos literários recorrentes. Parecia ter uma visão à frente do seu tempo. Sempre atento às questões, principalmente sociais, do Rio de Janeiro, participou ativamente de momentos contundentes na história brasileira, ao exemplo da passagem do Império para o Regime Republicano. Extremamente conhecido como literato, além de funcionário público, vivia muito próximo aos discursos de uma classe dominante. Essa convivência com a alta sociedade o fez ver mais de perto as teias que iam constituindo as redes de dominação e de reprodução do sistema patriarcal brasileiro na virada do século XIX para o XX.

A partir desse breve resumo biográfico de Andradina de Oliveira e de Machado de Assis, são percebidas algumas aproximações em relação à preocupação com as disparidades sociais. Isso fica ainda mais notório na medida em que no romance $O$ perdão, Andradina de Oliveira vai à gênese do sistema patriarcal ao denunciar as formas dominação masculina a partir do cárcere da mulher no casamento. Ao encontro disso, Dom Casmurro, de Machado de Assis, também retrata uma mulher aparentemente presa ao matrimônio desde a sua infância, usando de artimanhas para constituir um casamento que lhe favorecesse socialmente. Além disso, as congruências existentes nesses dois romances aqui articulados tornam-se ainda mais representativos na medida em que partem do mesmo eixo temático: o adultério.

Por fim, se torna bastante apropositado, dessa forma, analisar como se dá a construção da personagem feminina e das relações familiares na ótica de 
Andradina de Oliveira no seu romance, se comparado ao de Machado de Assis. Ainda que de maneira breve, por se tratar de uma pesquisa em fase inicial, este artigo pretende-se como uma forma de análise e interpretação do texto literário a partir de uma epistemologia comparatista. Além disso, tem-se como intuito perceber quais eram as vicissitudes e aproximações, que sentido tinha a mulher na sociedade e quais eram suas expectativas (na visão de cada um dos autores).

A histórica limitação da mulher em escrever seus pontos de vista a partir da literatura faz com que seja primordial, cada vez mais, uma análise intertextual dos romances no que se refere à questão do gênero. Para tanto, compreende-se necessário estabelecer algumas questões teóricas da Literatura Comparada, com um célere percurso de sua formação. Dessa forma, as reflexões se darão principalmente sobre as décadas finais do século $X X$, pensando em suas asserções sobre o cânone na literatura e o discurso oficial.

Segundo Alós e Schmidt (2009), nesse intuito, compreende-se que somente em fins dos novecentos, ao traçar métodos de análise que compreendam as escrituras periféricas (não europeizadas), que se puderam estabelecer estudos mais aprofundados sobre a alteridade e a diferença entre os estudos literários. Dessa forma, a teoria contemporânea viabiliza o estudo das minorias excluídas pela crítica oficial. Além disso, não somente as escrituras femininas ganham espaço conceitual, mas, também, as postulações étnicas, raciais, homossexuais e, de maneira geral, os países de terceiro mundo.

A partir desses questionamentos que se mostram cada vez mais intensos desde meados da década de setenta, pode-se constatar que a teoria está progressivamente voltada ao que foi execrado pela crítica oficial. Para Schmidt (2007), a tonificação que a área das Humanidades vem semeando com uma postura mais interdisciplinar, sublima os processos que geram um aprofundamento das questões sobre as minorias. Desse modo, a constituição das subjetividades e das identidades, assim como a própria natureza do político, simbolizam as novas figurações analíticas, construindo sentidos diversos aos calcados pela tradição. Inserindo a Teoria Literária no contexto das materialidades históricas, nas relações de produção e nas especificidades 
culturais que perfazem as engrenagens sociais, são desnuviadas as disputas pelo direito à voz, à justiça e, consequentemente, pelo reconhecimento de outras escriturais literárias não canônicas.

Além disso, foi nesse período que houve o surgimento da categoria "gênero", fazendo mais profícua a expansão das teorias feministas. Conforme Hollanda (1994), tal processo ocorre através da obliteração da noção de identidade em detrimento do estudo sobre o processo que constitui as relações de poder que criam essas identidades. A partir de uma contestação histórica e social da manutenção desse sistema identitário, corrobora para inviabilizar as diferenças sexuais como "naturais".

Através dessa conjuntura foi que se consolidaram algumas proposições dentro da disciplina de Literatura Comparada que, segundo Eduardo Coutinho: "são problemas como o das relações entre uma tradição local e outra importada, das implicações políticas da influência cultural, da necessidade de revisão do cânone literário e dos critérios de periodização" (1996, p. 69). Nesse sentido, como é percebido por Alós (2012a), a proeminência de determinados discursos em detrimento de outros, revelava-se preconceituosa ao considerar apenas o cânone como paradigma de referência e valoração estética. Sob o aporte da Literatura Comparada, as obras literárias começam a ganhar outras conotações avaliativas, dialogando com questões culturais, sendo que:

\footnotetext{
[...] os critérios valorativos/judicativos passam a oscilar a partir do locus de enunciação do comparatista [..] A literatura comparada, desta forma, renova-se, problematizando os pressupostos paradigmáticos da teoria da literatura e fazendo a crítica forçar-se a uma metacrítica, no sentido de conscientizar-se do seu locus político e enunciativo [...] (Alós, 2012, p. 12a).
}

A relativização ou, pelo menos, a flexibilização dos processos canônicos permitem o surgimento de escritores excluídos pela crítica, abrindo um importante espaço para o surgimento de novas perspectivas e percepções culturais. É nesse sentido que Anselmo Peres Alós (2012b) propõe a possibilidade de novos cânones na literatura, reivindicando um espaço até então renegado pelo discurso oficial, no qual a crítica feminista vem se debruçando. Através de trabalhos que se dedicam ao resgate de uma 
produção deslocada do sistema "heteronormativo", obras literárias de cunho feminino ganham espaço entre os postulados canônicos, desconstruindo a rigidez de dos valores estéticos, supostamente homogêneos que foram até então instituídos.

Pensando nos dois romances aqui propostos, podemos considerar que o cânone machadiano teve um papel de vanguarda, principalmente para os escritores homens, ao desmistificar as formas de conduta das mulheres oitocentistas. Contudo, mesmo que boa parte de suas personagens femininas contenham uma articulação bastante manipuladora sobre os personagens homens em suas tramas, algumas características podem ser analisadas com maior atenção. Em relação a isso, podemos perceber que no romance Dom Casmurro a identidade de Capitu - personagem principal - é acobertada, de maneira que temos apenas uma única versão para os fatos que se apresentam. O que o autor nos relata é como Bentinho percebia a situação. Apenas uma das partes interessadas tem o poder de fala: o sujeito homem.

Ao percorrer esse caminho, Machado de Assis parece estar, a princípio, condescendente com os discursos patriarcais que se alastravam ainda no período republicano brasileiro. Nesse sentido, diante dos impasses da traição e do adultério, podemos nos perguntar: como as mulheres se viam ou o que elas teriam a dizer, diante do retrato imposto pela ótica masculina da época, em se tratando da fidelidade nos laços matrimoniais?

Recorrendo às ferramentas que a Literatura Comparada nos permite, mais especificamente a interdisciplinaridade, podemos pensar o contexto social do romance sob um prisma histórico. Debruçando-se em analisar documentos concernentes ao século XIX (laudos médicos, jornais, arquivos de igrejas, etc.), Mary Del Priore (2012) enfatiza a objetificação da mulher até o início do século XX, quando eram tratadas de maneira geral como uma propriedade. Nesse sentido, o prazer sexual apenas se destinava aos homens, enquanto que para as mulheres meramente cabia a leitura de romances na clausura de suas casas. Além disso, também chama a atenção a hipocrisia social desse período, na medida em que os desejos femininos eram extremamente proibidos, tornando malogrado o matrimônio. A sexualidade era extremamente regulada, mas ao homem e apenas a ele, cabia a possibilidade do adultério. 
Nesse sentido, não se torna difícil perceber que as mulheres da virada do século teriam muito a dizer sobre esse assunto. Mas isso não é oportunizado na narrativa machadiana. Por outro lado, podemos constatar algumas singularidades apresentadas no perfil das personagens que permitem direcionamentos avessos aos traçados amiúde pelos principais escritores da época. Capitolina Pádua, mesmo sob a ótica de Bentinho, é personificada como uma mulher astuciosa e determinada que, através de dissimulações e muita perspicácia, consegue angariar um casamento que the permite melhor status social. Esse tipo de comportamento entra em desacordo com os pressupostos românticos do período, os quais viam as mulheres como submissas aos postulados patriarcais.

Ao encontro disso, torna-se desnecessário dizer que o postulado canônico machadiano é altamente creditado à sua postura crítica em relação à sociedade brasileira. Tendo como base esse princípio, esse artigo irá propor uma investigação que compreenda determinados pontos, dentre as diferentes formas que Andradina de Oliveira, narrando em primeira pessoa, analisa as relações familiares burguesas, concebendo, principalmente, o papel da mulher na ótica da escritora e fazendo um contraponto com as percepções do bruxo do Cosme Velho.

Ao contrário da protagonista machadiana, Estela provém de uma família nobre do Rio Grande do Sul, onde o matrimônio é visto apenas como uma confirmação e manutenção do status quo na sociedade. Além disso, em princípio não há qualquer tipo de dissimulação por parte dela para conquistar Jorge, tudo se dá dentro das normas convencionais e tradicionais da época: a mulher aceita o casamento vendo-o como um bom negócio para a família, assim agradando ao seu pai.

Enquanto que para o escritor Machado de Assis a traição de Capitu é tratada de forma dúbia e apenas sugestiva através das memórias de Bentinho, Andradina de Oliveira propõe a crueza do desejo sexual feminino, fazendo do próprio ato do desejo uma das marcas principais de sua personagem. A relação de Estela com Armando é assinalada pela intensidade tanto física quanto psíquica, causando calafrios, insônias, suores e pensamentos "poluídos". 
Essa vivacidade sexual que Estela carrega se torna importante na medida em que, até então, cabia às mulheres apenas o fado reprodutivo. Esse tipo de personagem permite uma revisão histórico/literária diferenciada do que até então fora instituído pela crítica oficial. Estando as mulheres historicamente instituídas no imaginário social apenas pelo arbítrio idealizado pelo patriarcalismo, a narrativa de Andradina de Oliveira acaba por realocar o significado da mulher na história da literatura. Assim, como bem observa Schmidt:

se o cânone literário é a narrativa autorizada dessa memória, pode-se dizer que o resgate da autoria feminina do século XIX traz à tona, de forma explosiva, aquilo que a memória recalcou, ou seja, outras narrativas do nacional que não só deixam visíveis as fronteiras internas da comunidade imaginada como refiguram a questão identitária nos interstícios das diferenças sociais de gênero, classe e raça, reconceptualizando, assim, a nação como espaço heterogêneo, mais concreto e real, atravessado por tensões e diferenças. Pelo viés da ótica feminina, nacionalizar o nacional, o que soa aparentemente como um despropósito, significa, justamente, questionar a matriz ideológica do paradigma universalista que informou o princípio do nacionalismo brasileiro, responsável pela constelação hegemônica de forças políticas, sociais e culturais presentes na formação e no desenvolvimento da nação como narração. Talvez essa seja uma das explicações para o silêncio e a exclusão de nossas escritoras da historiografia literária, da moderna tradição crítica e da história das ideias no Brasil, já que mostrar o país, na perspectiva de muitas delas, era problematizar as bases das ideologias masculinas de nação". (2000, p. 89)

Pensando os textos literários como artefatos culturais com capacidades de produzir e espraiar valores na sociedade em que se inserem, percebe-se que essa relação intertextual pode conduzir a um ato performoativo desestabilizador (Butler apud Alós, 2012). Na medida em que as mulheres eram compreendidas apenas como um objeto reprodutor, o paralelo incutido em $O$ perdão produz um capital simbólico que altera as percepções de mundo. As possibilidades eróticas, quando exploradas e fugindo do seu caráter moralista/patriarcal, redimensionam significados agindo performoativamente no espaço social. Dessa forma, percebe-se a impossibilidade de preexistir uma identidade de gênero como um atributo que possa ser medido e, quando instituído, não passaria de um ato ficcional regulador. 
Com essa breve contextualização intertextual dos dois romances, podemos notar que a crítica à sociedade burguesa, tão cara a fama de Machado de Assis, se institui de forma ainda mais intensa na narrativa de Andradina de Oliveira. Dessa forma, as possibilidades analíticas que se instituem - e que extrapolariam os limites desse trabalho se levadas todas ao cabo - instigam uma releitura dos pressupostos canônicos através da dialética que uma obra literária pode estabelecer com uma outra obra primeira. Podemos considerar que o romance de Andradina de Oliveira subverte a ordem estabelecida, além de redimensionar o papel feminino na crítica literária, ao propor uma visão mais crua e objetiva da sua realidade social. Em tom de denúncia, a mulher que não consegue minimamente suprir as suas vontades mais instintivas por viver enclausurada nas relações sociais patriarcais, acaba se despindo de todos os valores que a cercam: o homem, a família, os bens materiais e, talvez constituindo valor apenas para ela, a própria vida.

\section{REFERÊNCIAS}

ALÓS, Anselmo Peres. A literatura comparada neste início de milênio: tendências e perspectivas. Ângulo (FATEA), n. 130, jul./set. 2012. p. 7-12. Disponível

em: <http://www.fatea.br/seer/index.php/angulo/article/view/1007/787.> Acesso em: 07 nov. 2014b.

ALÓS, Anselmo Peres. Literatura comparada ontem e hoje: campo epistemológico de ansiedades e incertezas. Organon. (UFRGS), Porto Alegre, v. $27, \quad$ n. $52, \quad 2012$, p. 17-42. Disponível em: <http://seer.ufrgs.br/index.php/organon/article/view/33469/21342> Acesso em: 04 dez. 2014a.

ALÓS, Anselmo Peres. Texto literário, texto cultural, intertextualidade. Revista Virtual de Estudos da Linguagem - ReVEL. Vol. 4, n. 6, março de 2006. p. 1$25 . \quad$ Disponível em: <http://www.revel.inf.br/files/artigos/revel_6_texto_literario.pdf.> Acesso em: 28 nov. 2014.

ALÓS, Anselmo Peres. A letra, o corpo e o desejo: masculinidades subversivas no romance latino-americano. Florianópolis: Ed. Mulheres, 2012.

ALÓS, Anselmo Peres; SCHMIDT, Rita Terezinha. Margens da poética/Poéticas da margem: o comparatismo planetário como prática de resistência. Organon, Porto Alegre, n. 47, julho-dezembro, 2009, p.129 - 145c. 
ASSIS, Machado de. Dom Casmurro. São Paulo: Gráfica Editora Brasileira LTDA, 1947.

CHALHOUB, Sidney. História em cousas miúdas. Campinas, São Paulo: UNICAMP, 2005.

COUTINHO, Eduardo. Literatura comparada, literaturas nacionais e o questionamento do cânone. Revista Brasileira de Literatura Comparada. Rio de Janeiro, n. 3, p. 67-73, 1996. Disponível em: <http://www.abralic.org.br/download/revista/Revista_Brasileira_de_Literatura_C omparada_-_03.pdf> Acesso em: 01 nov. 2014.

DEL PIORE, Mary. História do amor no Brasil. 3. ed. São Paulo: Contexto, 2012.

HOLLANDA, Heloísa Buarque de. Feminismo em tempos pós-modernos. In: (Org.). Tendências e impasses: o feminismo como crítica da cultura. Editora Rocco: Rio de Janeiro, 1994, p. 7-19.

SCHMIDT, Rita Terezinha. A literatura comparada neste admirável mundo novo. Revista Brasileira de Literatura Comparada. N. 11, p. 11-35. São Paulo, 2007. Disponível em: <http://www.abralic.org.br/download/revista/Revista_Brasileira_de_Literatura_C omparada_-_11.pdf> Acesso em: 24 nov. 2014.

SCHMIDT, Rita Terezinha. Mulheres reescrevendo a nação. Estudos Feministas. Vol. 8, n. 1, p. 84-97. Florianópolis, jan./jun. 2000. Disponível em: <https://periodicos.ufsc.br/index.php/ref/article/view/9858/9091> Acesso em: 02 dez. 2014. 